\title{
As esferas do reconhecimento: uma introdução a Axel Honneth
}

\author{
Suzana Guerra Albornoz \\ Universidade de Santa Cruz do Sul
}

Este ensaio considera os padrões de reconhecimento intersubjetivo - o amor, o direito e a solidariedade -, no livro de Axel Honneth, Luta por reconhecimento - a gramática moral dos conflitos sociais. De modo resumido, apresenta a distinção das três esferas do reconhecimento - a dos afetos e da autoconfiança; a das leis e direitos, do auto-respeito; a da solidariedade social e da autoestima. Recorda-se a teoria do reconhecimento de G.W.F. Hegel, primeira referência da reflexão de Honneth, bem como, também, a de G. Mead e a de D. Winnicott, a que o autor dá especial atenção. Desejam-se sugerir, na tradição crítica e dialética, novas linhas para a pesquisa dos estudiosos das relações nos âmbitos do trabalho, do lazer, da educação.

Palavras-chave: Axel Honneth, Reconhecimento, Dinâmicas sociais.

The spheres of recognition: an introduction to Axel Honneth

This essay considers the patterns of inter-subjective recognition - love, right and solidarity - in the book of Axel Honneth, Struggle for recognition: the moral grammar of social conflicts. In a short way, it presents the distinction of the three spheres or dimensions of recognition - that of the affections and the self-confidence; that of the laws and rights, of the self-respect; that of the self-esteem and social solidarity. It is remembered the theory of recognition of G.W.F. Hegel, first reference of the reflection of Honneth, and also those of G. Mead and D. Winnicott, to whom the author pay special attention. The aim is to suggest, in the critical and dialectical tradition, new lines to serve the researchers of work, leisure and educational relationships.

Keywords: Axel Honneth, Recognition, Social dynamics.

\section{Introdução}

$\mathrm{N}^{\circ}$ o momento atual das ciências humanas, logo, na psicologia social e também nas ciências da educação, é difícil dizer algo novo se não for num estudo de caso, numa amostragem de uma situação empírica muito peculiar. Quando se está preocupado com a reflexão sobre situações menos particulares, percebe-se que é preciso trabalhar junto à contribuição de autores já reconhecidos, dos clássicos aos contemporâneos mais eminentes, de modo a nos atualizarmos e, embora conservando nossa distância crítica e lucidez, acertar nosso passo com o deles, para levar adiante a construção da reflexão. Por isso escolhemos escrever este breve ensaio, fazendo uma apresentação de parte da teoria do reconhecimento numa das primeiras obras de Axel Honneth, e assim, pelos textos de Honneth e de seus autores de referência - como Hegel, Mead e Winnicott, destacar um aspecto da sua reflexão que me parece significativo, próprio a enriquecer e inspirar pesquisas nas áreas das ciências sociais e da educação.

Ante a atual situação do trabalho, em evidente transformação por causa das novas tecnologias, o incremento da automação e o uso da inteligência artificial, decorrendo daí novas formas de desemprego no setor industrial e novas áreas de atividade humana, fenômenos sobre os quais refletem obras bem conhecidas ${ }^{1}$, somos desafiados a repensar suas consequências sobre a psicologia das novas gerações e sobre os problemas que as mudanças expõem, entre os quais

1 Como, por exemplo, Império, de Michael Hardt e Toni Negri, e O horror econômico, de Viviane Forrester. 
se destaca a questão do reconhecimento intersubjetivo, da autoestima e da afirmação social, passíveis de ocorrer de modo às vezes independente, se não exterior às teias da produção. Tais transformações no plano do trabalho, que influem nas dinâmicas intersubjetivas e sociais de reconhecimento, encontram-se no centro da preocupação e da responsabilidade dos profissionais da pedagogia e da psicologia de caráter social.

Além da reflexão sobre a relação evidente entre reconhecimento e inserção no mundo do trabalho, realidade central nas ciências humanas dos últimos séculos, porque também central na civilização capitalista moderna, não foram esquecidas as valorações mais antigas, próprias de outras culturas e outras épocas que tomavam o ócio como oportunidade de elevação e aperfeiçoamento dos sujeitos, pressupondo o valor do ócio. No pequeno livro com sentido de manifesto que já tive a oportunidade de apresentar ${ }^{2}$, o escritor socialista, francolatino-americano, Paul Lafargue, abre uma janela para o entendimento do humano como vida que vale mais do que o trabalho, compreensão corroborada pelas interpretações históricosociológicas de Max Weber ${ }^{3}$, que participam da crítica das pressões escravizantes do trabalho industrial. Em ensaio anterior, também tive ocasião de lembrar as teses antropológicas de Johann Huizinga, em seu rico trabalho de pesquisa ${ }^{4}$, no qual a afirmação da realidade originária do jogo, como subjacente e anterior à do trabalho, anterior mesmo à da cultura, impõe repensar os conceitos sobre a identificação demasiado imediata do trabalho com o humano. A mesma atitude de distanciamento da ideologia do trabalho é proposta pela construção conceitual de Hannah Arendt, que se debruça de modo muito especial sobre a liberdade e a pluralidade que constituem a ação política ${ }^{5}$, para afirmar contra a corrente mais comum dos nossos tempos sombrios, a dignidade da política, e para antecipar a superação da centralidade do trabalho produtivo, na realidade histórica como na análise da condição do gênero humano. Em certa medida, é esse, igualmente, o efeito das teses do sociólogo do trabalho Domenico De Masi ${ }^{6}$.

Lafargue e Huizinga, assim como, depois, Arendt e, ainda hoje, De Masi, nos convidam a balançar os preconceitos modernos do reconhecimento como exclusivamente ligado à manifestação produtiva, ao nos recordarem os valores clássicos do ócio, os quais o ligam à teoria, ao espírito e à ação. Segundo Arendt, em A condição humana, em que se evidencia a inspiração na memória da cultura grega e nos filósofos do período clássico da antiguidade ateniense, nessa compreensão de vita activa, além do trabalho, o labor e a práxis, mantém-se, superior, a possibilidade de exercício da teoria, ou seja, a atividade do espírito na contemplação que, no pensamento insuperável de Aristóteles, vem a ser a condição da felicidade. A contemplação, na filosofia grega - talvez já na cultura grega -, tinha o sentido de atividade teorética, como filosofia e conhecimento científico. Posteriormente, passou-se a compreender o termo pelo seu aspecto religioso, como contemplação no sentido de dedicação mística, de oração. Mas, de todo modo, a ausência de envolvimento no trabalho produtivo era requerida como precondição para a terceira categoria da atividade humana - a da ação política ou práxis, considerada pelos antigos gregos como a única atividade livre, por isso aquela propriamente humana.

O lugar de honra do valor do ócio, que nos advém da tradição, desde os gregos, não impede a consciência crítica em relação ao uso do ócio na modernidade. A crítica do tempo livre planejado na cultura de nosso tempo tem sido realizada, sendo um exemplo, um caso paradigmático, a crítica da indústria cultural feita por Theodor Adorno, que podemos encontrar através das interpretações e comentários de Rodrigo Duarte ${ }^{7}$. A crítica do lazer na

\footnotetext{
2 Ver meu texto Sobre O direito à preguiça de Paul Lafargue (Albornoz, 2008).

3 Em seu clássico Ética protestante e espírito do capitalismo, 1904/1905.

4 Como se vê em Homo Ludens (1938).

5 The human condition (1958), A dignidade da política e outras obras esclarecem o conceito de ação de Hannah Arendt.

6 É dele o conceito de "ócio criativo" que, não sendo trabalho, também não é só dolce far niente.

7 Em Teoria crítica da indústria cultural, R. Duarte trata o tema em autores da Escola de Frankfurt, destacando Adorno.
} 
sociedade burguesa aparece também de modo muito especial nos textos da filosofia da utopia de Ernst Bloch ${ }^{8}$, como oposto à recreação de qualidade cultural e utópica que ainda pode ser identificada nas estreitas brechas abertas na experiência, que permitem fugir da padronização banal do lazer comercial na sociedade capitalista.

A realidade das transformações atuais do trabalho convida a repensar a dinâmica das relações sociais nas quais se dão as redes do reconhecimento intersubjetivo; e é isso que vem sendo realizado, de modo instigante, por um dos mais destacados autores, pode-se dizer o nome mais representativo da terceira geração da Escola de Frankfurt - discípulo de Habermas ${ }^{9}$, sociólogo e filósofo contemporâneo, Axel Honneth ${ }^{10}$, cujas ideias sobre a gramática moral dos conflitos sociais, em torno da trama do reconhecimento, podem fecundar a reflexão sobre as relações atuais entre trabalho e ócio. Retomaremos aqui a reflexão de Honneth em seu livro Luta por reconhecimento, publicado em $1992^{11}$, nela buscando colher inspiração para a consciência das responsabilidades que, assim como em todas as épocas e, justamente, de modo marcado pela época, constituem hoje a tarefa dos estudiosos das ciências do homem, sobretudo aqueles que mantêm uma especial preocupação prática, como os psicólogos do trabalho e os educadores.

\section{A luta de vida ou morte na dialética do reconhecimento segundo Hegel}

A afirmação moderna do reconhecimento intersubjetivo na dinâmica do poder e do trabalho foi construída especialmente no momento idealista da filosofia de Georg Wilhelm Friedrich Hegel (1770-1831), com sua descrição, em nível especulativo, da dialética efetiva das relações entre o senhor e o servo, como foi expresso nos textos de juventude do filósofo ${ }^{12}$. A seguir, tomou forma no momento teórico materialista, da análise da alienação do trabalho no capitalismo industrial por Karl Marx ${ }^{13}$. Esses são apenas alguns dos antecessores das análises de Axel Honneth, que se refere também a outros autores contemporâneos; contudo, as teses clássicas do estudante de teologia de Tübingen permanecem vivas sob a teoria crítica do discípulo de Frankfurt. E em sua análise da luta pelo reconhecimento, Honneth efetivamente começa pela tese da luta de vida ou morte no pensamento do jovem Hegel ${ }^{14}$. A dialética do senhor e do escravo, tal como expressa na Fenomenologia do Espírito, encontrava sua preparação, um dos seus textos antecipadores, no Anexo da Filosofia Real de Jena. Parece-me interessante recordar, diretamente no texto de $\operatorname{Hegel}^{15}$, o conteúdo dessa referência da análise de Honneth.

8 Conferir em Princípio esperança (vol. 2, 437ss), sobretudo pp. 472-477. Ver meu texto Tempo livre e humanização: dúvidas e esperanças ante as novas possibilidades de lazer (Albornoz, 2010).

9 Jürgen Habermas, nascido em 1929, com Adorno e Horkheimer, é um dos mais conhecidos mestres da Escola de Frankfurt. Importa lembrar sobretudo a obra Teoria da ação comunicativa, 1981.

10 Axel Honneth é bem conhecido no Brasil, apresentou conferência no Instituto Goethe de Porto Alegre ainda em 2009.

11 Um leitor exigente perceberá que não levei em conta outras obras do autor, sendo que sua teoria continuou a desenvolver-se e, em obras posteriores, várias das teses aqui relatadas foram modificadas. Também é verdade que, para uma análise mais completa, deveria explorar melhor a literatura secundária sobre a teoria do reconhecimento.

12 Conferir os escritos hegelianos do período em que lecionou em Jéna, da Filosofia do espírito, sobretudo o Anexo da Filosofia Real de Jena chamado O fragmento do sistema, constituído de escritos de 1803 e 1804. Tais escritos dos primeiros anos do século XIX se completam nas obras mais maduras, como a Fenomenologia do espírito, mas quanto ao reconhecimento, têm sua completude própria.

13 Explícita nos Manuscritos filosóficos de 1844, conhecidos e interpretados desde 1934.

14 Aqui utilizo minha tradução de trechos do Fragmento do sistema, incluída em trabalho apresentado para crédito acadêmico no Mestrado em Filosofia na UFRGS, em 1981 (tradução corrigida por Peter Naumann, tradutor-intérprete, e Günter Kipfmüller, então diretor de cursos no Instituto Goethe de Porto Alegre).

15 São escritos de 1803 e 1804. Uso especialmente A terceira potência da posse e da família, pp. 319- 327. 
Em sua linguagem enigmática particular, o mestre de Jena disserta sobre a necessidade do reconhecimento recíproco das "totalidades singulares de consciência". Para introduzir a compreensão da dialética das consciências, usa a família como metáfora, como explicação para a trajetória que leva ao surgimento da consciência, como "totalidade singular" envolvida no necessário reconhecimento recíproco. "Ideal" e "real" se movimentam na relação dos pais com a criança, na qual suspende-se a consciência dos pais, sendo a própria criança uma consciência suspensa, enquanto se forma e torna culta às expensas da consciência dos pais:

Assim se produz a consciência para si mesma como identidade do interior e do exterior. $\mathrm{Na}$ família, a totalidade de consciência é um ente em devir para si mesmo, em que o indivíduo se percebe a si mesmo no outro. É absolutamente necessário que a totalidade a que chegou a consciência na família possa reconhecer-se como si mesma em uma outra totalidade de consciência como tal. (...) Neste reconhecer, cada um se põe na consciência do outro, suspende a singularidade do outro; ou cada um põe em sua consciência o outro como uma absoluta singularidade da consciência (Hegel, 1970, pp. 320-321).

Hegel enfatiza ser esse o reconhecimento recíproco, e afirma como ele só pode existir "como a apresentação de uma totalidade singular de consciência em outra totalidade de consciência" (Hegel, 1803/1970). É acentuada a tensão do singular e do universal, na relação das totalidades de consciência. O filósofo aponta para o caráter "comum" ou "indiferente" da consciência, enquanto participa da realidade ideal do mundo - a comunidade de consciências. Assim,

o singular é só uma consciência, na medida em que cada singularidade de sua posse e de seu ser aparece ligada a toda a sua substância, é tomada em sua indiferença, na medida em que ele a cada momento se põe como si mesmo, pois isso é a consciência, o ser ideal do mundo (Hegel, 1970, p. 321).

Um dos traços marcantes dessa teoria do reconhecimento é que este se caracteriza pela contradição, ou seja, se realiza como oposição, mesmo como lesão ou ofensa. "A lesão de uma de suas singularidades é por isso infinita, uma ofensa absoluta, uma ofensa a ele como parte de um todo, uma ofensa de sua honra; e a luta por cada singularidade é uma luta pelo todo" (Hegel, 1803/1970). A singularidade de cada totalidade de consciência, justamente por sua singularidade, leva-a a excluir as outras totalidades singulares de consciência. Se o reconhecimento recíproco é necessário, porque a totalidade singular de consciência só sabe de si mesma quando se reconhece como consciência suspensa no outro, na consciência oposta, contudo, isso não se dá sem tensão. A singularidade da consciência exclui a outra consciência: "suspende-a". Ambas precisam reconhecer-se mutuamente, pois só existem como partes de um todo dinâmico de consciência que as engloba, mas ao se reconhecerem, se opõem:

Como esta totalidade, apresentam-se ambos um contra o outro, e querem saber-se reconhecidos como essa totalidade de singulares postos um contra o outro; e a condição de que se deem um contra o outro é: a) que cada um apareça na consciência do outro como tal, o que o exclui de toda a extensão de sua singularidade; e b) que, nesse seu excluir, ele seja realmente totalidade (Hegel, 1970, pp. 321-322).

Por serem partes de um todo dinâmico de consciência, enquanto ambos os indivíduos se opõem, a lesão que um pode causar ao outro é uma lesão "infinita", uma ofensa "absoluta". Dito de outro modo: a opressão da consciência singular instaura o processo de opressão da consciência universal. A dominação sobre uma totalidade de consciência, lesada e ofendida sua singularidade no processo de reconhecimento, atinge o "todo": a humanidade da humanidade, o "ser ideal do mundo". Na luta entre as consciências singulares, no seu confronto, reconhecimento e lesão, não está em jogo apenas a singularidade de cada consciência, mas a consciência universal. Particular e universal são os dois polos de uma mesma linha curva e 
retesada. Se há uma sombra empírica lançada pela categoria do reconhecimento como lesão, é a insinuação de um cego determinismo: por ser totalidade singular de consciência, preciso ser reconhecido; por ser singular, e ter necessidade de reconhecimento do outro, enquanto me vejo nele e o tenho como outro em mim, oponho-me ao outro como singular; excluo a singularidade dele e ele exclui a minha. Ofendemo-nos em nossa singularidade, enquanto nos reconhecemos como um suspenso no outro e do outro; e ao nos ofendermos, a ofensa atinge a vida da consciência que nos sustenta a ambos. Assim, por sermos seres singulares de consciência, lesamos a vida da consciência como ser ideal.

Por esse caminho de reflexão dialético, encaminha-se a teoria do meio real do reconhecimento: Se não me reconheço no outro nem o reconheço, ambos que somos seres suspensos um no outro e um contra o outro, que nos lesamos e ofendemos por sermos singulares e em relação com o todo da consciência, não nos reconhecemos nem lesamos por meios "ideais". O reconhecimento se dá num meio "real", quer dizer, por meio das coisas:

Isso ninguém pode provar ao outro, através de palavras, garantias, ameaças ou promessas, pois a linguagem é só a existência ideal da consciência; aqui, porém, são reais, absolutamente opostos, seres que são absolutamente para si e um contra o outro, e sua relação, por excelência, ela mesma é uma relação prática real; o meio de seu reconhecimento precisa ele mesmo ser real (Hegel, 1970, p. 322).

A leitura de tais frases balança os preconceitos fáceis que se pode ter sobre o idealismo de Hegel. Quando se lê "relação prática, real", entende-se relação através de coisas, como a relação que se estabelece entre duas "totalidades singulares de consciência", quando entre elas estão envolvidas realidades concretas, tais como trabalho, propriedade, coisas (o gozo da posse, das coisas, da posse de coisas); enfim, meios concretos, que tornam a relação real. Por esse viés se introduz na análise a questão da dominação. $\mathrm{O}$ reconhecimento recíproco das consciências como singulares e opostas, uma como suspensa na outra e pela outra, que a exclui como singular e ao mesmo tempo lhe devolve a sua consistência, não é uma fantasmagoria, uma ficção, uma forma abstrata, uma descrição ideal, mas alude a um confronto concreto, prático, real. Se não pode ser tomado como descrição psicológica, é uma categoria de interpretação dos fenômenos concretos da interação humana.

Por outro lado, a contradição no reconhecimento se situa na posse. Em sua posse, cada um precisa ser perturbado, especial e necessariamente, pois na posse se situa a contradição; que um exterior, uma coisa, um fato universal da terra, que isso deva estar no poder de um singular, é contra a natureza da coisa como exterior universal; e é o universal contra a imediata singularidade da consciência (Hegel,1970, p. 323).

Singularidade e universalidade entram em conflito na posse. A coisa, o objeto da propriedade sendo o fato universal da terra, repugna deixá-la/o sob o poder ou na posse de um ser singular que, no entanto, aspira afirmar sua singularidade na posse da coisa e, em sua singularidade, é perturbado quando impedido de possuir. Eis a contradição: os indivíduos desejam possuir para afirmar sua singularidade, mas a coisa a ser possuída existe como um exterior universal, e é contraditório deixar um universal sob o poder de um indivíduo. Essa contradição se reproduz ante cada um dos indivíduos opostos e na sua oposição mesma, constituindo a substância da sua oposição. Como o meio do reconhecimento é um meio real, na questão da posse é que se efetiva o reconhecimento como lesão e ofensa.

A lesão necessária deve levar ao reconhecimento. Para lidar com a contradição situada na posse - no meio real do reconhecimento, que consiste em o indivíduo singular desejar a posse da coisa que é exterior universal, a única transição possível é a lesão, o ferimento de uma consciência pela outra consciência singular. Através da lesão que deve levar ao reconhecimento, colocam-se ambos na condição de contrapostos, como totalidades singulares 
negativas e absolutas; enquanto cada um exclui com violência o outro e suspende a posse tomada na lesão, ao mesmo tempo, fere o outro e nega no outro algo que considera como seu. Pela violência da afirmação da singularidade criam-se as condições da contraposição igualitária. Lesando o outro na sua pretensão de possuir o exterior universal, contraponho-me a seu desejo indevido, firo algo que considera como seu, mas é só assim que posso afirmar a mim mesmo, como outro indivíduo singular, do mesmo modo desejoso de posse e de reconhecimento; é pela lesão que chego ao reconhecimento.

Por isso, há uma dialética de vida ou morte na afirmação da singularidade:

\begin{abstract}
Cada um precisa afirmar o negado no outro como sendo em sua totalidade, como um não exterior, e suspendê-lo no outro; e no momento em que, neste singular, cada um afirma, por excelência, sua totalidade como a de um singular, então pode observar-se o fenômeno de que cada um nega a totalidade do outro. $O$ reconhecer recíproco da totalidade singular de cada um, pelo fato de ser singular e negada, como acontece na relação, torna-se uma relação negativa da totalidade. Cada singular precisa assim pôr-se como totalidade na consciência do outro, até o ponto em que investe, contra o outro, toda a sua aparente totalidade, até o ponto em que arrisca sua vida na preservação de qualquer singularidade; e do mesmo modo cada um visará à morte do outro (Hegel, 1970, p. 323).
\end{abstract}

Para a afirmação da sua singularidade, cada indivíduo tenta pôr-se na consciência do outro, e o faz de modo tão abusivo, lesivo e violento, que acaba por ameaçar a vida e a singularidade do outro. E enquanto ameaça a afirmação da singularidade do outro, expõe-se a si mesmo à destruição, porque radicaliza o confronto das singularidades, e a própria relação de reconhecimento se torna uma relação negativa das totalidades singulares de consciência. Só posso me reconhecer como totalidade singular na consciência do outro, na medida em que me ponho como tal em sua consciência, que sou em minha exclusão uma totalidade de exclusão visando à sua morte. Por isso, pode-se falar de uma dialética de vida ou morte na luta por reconhecimento no pensamento de Hegel.

Visando à sua morte, exponho-me à morte e arrisco minha própria vida. Cometo a contradição de querer afirmar a singularidade de meu ser e de minha posse; e essa afirmação transita no sentido do seu contrário, a saber, que sacrifico toda essa posse e a possibilidade de toda posse e gozo, até a vida mesma. Cada indivíduo nega a totalidade do outro até o ponto em que arrisca sua vida na preservação da singularidade, chegando a visar a morte do outro, assim se expondo à morte. Querendo ao mesmo tempo afirmar "meu ser" e "minha posse", acabo por ameaçar a singularidade do outro, e essa radicalização da oposição me leva a "expor-me à morte", o que significa sacrificar toda posse e a possibilidade de toda posse e gozo. No momento em que me ponho como totalidade da singularidade, suspendo-me a mim mesmo como totalidade da singularidade, quero ser reconhecido nessa extensão de minha existência, em meu ser e minha posse; mas transformo isso na suspensão dessa existência, e somente serei reconhecido como racional, como totalidade, na verdade, na medida em que assim arrisco minha própria vida - visando à morte do outro - e suspendo a extensão de minha existência mesma, a totalidade de minha singularidade.

Se a busca da afirmação da singularidade leva as consciências singulares a um confronto tal que se põe em jogo sua vida e sua morte, e uma parece ameaçar a outra porque a posse se introduziu na sua relação, há, contudo, um recurso, inevitável e estratégico, para que o movimento do reconhecimento recíproco possa continuar-se: tornar-me um ser suspenso, "suspender a mim mesmo como totalidade da singularidade", "suspender esta extensão de minha existência mesma" e, assim, assumir-me como esse ser que se suspende a si mesmo, que enfrenta o risco de perder a própria vida visando à morte do outro, para afirmar sua singularidade que, no entanto, só pode existir como reconhecida e suspensa no outro. 
O movimento contraditório pelo qual, ao procurar afirmar sua singularidade, a consciência singular é levada a buscar a morte do outro, arriscando a própria vida, resulta em que, como a relação prática dos opostos leva ao reconhecimento só se houver a lesão na posse, a radicalização da perda da posse faz com que uma das totalidades singulares de consciência desapareça como singularidade livre e se torne "escravo do outro". A "morte" se associa à "escravidão"; a "vida" é apanágio da consciência que se afirma como consciência absoluta para si mesma, que vai ao combate até a morte, provando-se no enfrentamento. E se o movimento do reconhecimento recíproco se transformou nessa luta de vida ou morte, a decorrência é a dominação e a existência de senhores - os donos da "vida", as consciências "absolutas" para si mesmas, os que lesam a posse do outro - e de escravos, os que se perderam na perda de toda posse e aparecem para o outro como não-totalidades singulares. "Quando permanece parado em si mesmo dentro da morte, e suspende a luta antes de matar, então nem se prova como totalidade, nem reconhece o outro como tal" (Hegel, 1970, p. 324).

Quem não agride se escraviza; mas também não é mais capaz de reconhecer o outro tal como ele precisa ser reconhecido; assim se frustra o processo do reconhecimento recíproco; porém, esse impasse parece inevitável, uma vez que, para reconhecer-se, as singularidades se opõem, suspendem-se uma na outra e contrapõem-se na posse; são inevitavelmente lesadas uma pela outra, e a lesão acirra a luta até o ponto em que se põe em jogo a vida e a morte de ambas, e a solução dessa confrontação se faz pela morte ou dominação de uma, que se torna incapaz de reconhecimento; o reconhecimento recíproco permanece apenas como uma "idealidade", na categoria do possível, e não encontra sua realização.

Tal é a contradição do reconhecimento segundo Hegel: o reconhecimento das totalidades singulares de consciência é contraditório porque "deixa de ser no momento em que é". Porque ao se entrar na relação prática, inicia-se o processo de reconhecimento recíproco: cada "totalidade singular de consciência" se suspende no outro e suspende o outro em si, reconhecendo-se nele; mas, nesse mesmo reconhecer, lesa o outro, enquanto ambos visam à posse e acabam visando à morte um do outro; e assim, um deles se aniquila, é suspenso na perda da posse e na morte, torna-se escravo do outro e incapaz de reconhecimento; e assim o reconhecimento deixa de existir, ou seja, quando começa a existir, desaparece.

Este reconhecer do singular é, pois, absoluta contradição em si mesmo; o reconhecer é só o ser da consciência como uma totalidade em outra consciência, mas no momento em que se efetiva, então suspende a outra consciência; com isto, suspende-se o próprio reconhecimento. Não se realiza, mas sim, antes, deixa de ser, no momento em que é (Hegel, 1970, p. 325).

Isso é contradição, pois a consciência singular só existe enquanto reconhecida e, para ser reconhecida, suspende o ser do outro, suspendendo o próprio reconhecimento. Esse é o paradoxo que envolve a afirmação da individualidade: embora seja condição de seu ser o reconhecimento recíproco, este se frustra por causa da luta pela afirmação da individualidade; os indivíduos se contrapõem enquanto aspiram à posse e, em consequência, perde-se o próprio ser singular. Nós, que precisamos do reconhecimento um do outro, para o obtermos nos lesamos e ofendemos, e um de nós se anula ante o outro; nesse desacerto contraditório, é como se nos destruíssemos a ambos, uma vez que não atingimos o reconhecimento recíproco, condição para a nossa existência como consciências singulares; assim, nos suspendemos um ao outro. Seja qual for de nós que se ponha como escravo, seja qual for o que se ponha como dominador, a relação de dominação anula o reconhecimento e representa a morte da consciência.

Quando reconhecemos que a consciência total reconhecida só é no momento em que se suspende, esse é um reconhecer da própria consciência que faz a reflexão de si mesma em si mesma: 
pois que a totalidade singular, enquanto quer manter-se e ser como tal, se auto-sacrifica absolutamente, se suspende, e com isto faz o contrário daquilo que visa. Ela mesma só pode ser como uma consciência suspensa; não pode manter-se como uma consciência que é, mas apenas como uma que se põe como suspensa; e se põe a si mesma, com isto, aqui, como uma (consciência) suspensa, e só pode como tal tornar-se reconhecida imediatamente uma e a mesma (Hegel, 1970, p. 326).

Essa é a consciência reflexiva que se forma na dialética do reconhecimento: a consciência se percebe a si mesma como ser suspenso; é a totalidade singular de consciência que se percebe como ser suspenso no outro e pelo outro, e assim se percebe a si mesma como reflexiva. E a consciência reflexiva percebe o fracasso do reconhecimento; reflete sobre o processo de reconhecer, que só existe quando deixa de ser, e assim se reconhece como um ser apenas suspenso, que não efetiva seu reconhecimento recíproco das totalidades singulares de consciência. Logo, se reconhece como consciência reflexiva que se suspende das consciências singulares.

Essa é também uma consciência universal. Como consciência singular, só poderia ser se fosse reconhecida, e o confronto das consciências singulares se transforma na luta de vida ou morte que leva ao fracasso do reconhecimento; por isso, as consciências singulares só permanecem como seres suspensos e que se pensam a si mesmos como seres suspensos, e este ser suspenso das consciências singulares reflexivas se constitui na consciência universal.

Só a consciência universal é reconhecida, e ainda é universal e reconhecida como um ser suspenso, o ser suspenso das consciências singulares. A totalidade como singularidade é posta em si mesma como apenas possível, existindo só como tal quando está sempre pronta para a morte, como consciência que renunciou a si mesma, que até mesmo é como totalidade singular, como família e na posse e no gozo, mas essa condição é apenas uma condição ideal (Hegel, 1970, p. 327).

As reflexões de Hegel sobre a luta pelo reconhecimento como de vida ou morte tomaram forma na teoria da relação dialética entre o senhor e o escravo, e foram desenvolvidos ainda mais perfeitamente, como dissemos, em textos memoráveis de obras da maturidade do filósofo; por sua vez, a análise dialética hegeliana da relação entre senhor e servo influenciaria fortemente o pensamento posterior, como a tese marxista sobre a luta de classes, que manteve sua presença na teoria crítica da sociedade praticada pela sociologia no século XX, especialmente pela Escola de Frankfurt, a que se filia Axel Honneth. A teoria crítica, de maneira clara, tem sido importante na sociologia das relações de trabalho e, de modo particular, no Brasil, tem-se feito presente também nas interpretações críticas da realidade educacional. Também por isso, penso que explorar a teoria de Honneth da luta pelo reconhecimento, a partir de suas raízes na teoria dialética do senhor e do servo de Hegel, deve sugerir novas linhas para a pesquisa crítica das relações de trabalho em suas relações com a educação.

\section{As diversas esferas do reconhecimento: de Hegel a Mead}

O discípulo de Habermas ressalta que, em termos gerais, o modelo hegeliano se apoia na tese de que a formação do eu prático está ligada à pressuposição do reconhecimento recíproco entre dois sujeitos: quando dois indivíduos se veem confirmados em sua autonomia por seu respectivo oposito, podem chegar, de modo complementar, a uma compreensão de si mesmos como agentes autônomos e individuados. Por outro lado, faria parte essencial do modelo conceitual de Hegel também a tese na qual, partindo das premissas da teoria da 
intersubjetividade, afirma-se a existência de formas diversas de reconhecimento recíproco, que devem distinguir-se umas das outras segundo o grau de autonomia que, em cada caso, se possibilita ao sujeito. Em diversas obras hegelianas estaria a distinção de três esferas do reconhecimento - a do "amor", a do "direito" e a da "eticidade" -, três relações de reconhecimento, em cujo quadro os indivíduos se confirmam reciprocamente como pessoas autônomas e individuadas ${ }^{16}$.

Na visão de Honneth da história da questão, as três esferas do reconhecimento afirmadas por Hegel - em que evolui, como numa espiral ascendente, a formação da autoconsciência e do reconhecimento das pessoas, no movimento de confronto entre os sujeitos - encontram continuidade e complemento nas três dimensões do reconhecimento que aparecem na psicologia social de George Herbert Mead (1863-1931), cujo sistema teórico foi chamado de "interacionismo simbólico". A psicologia social desse autor, no que se refere à teoria do reconhecimento intersubjetivo, segundo Honneth, constitui uma ponte entre a ideia original de Hegel e o modo de pensar do nosso tempo, e os escritos de Mead poderiam ser vistos como uma tradução da teoria hegeliana da intersubjetividade numa linguagem teórica pósmetafísica.

Em Mead seria desenvolvida sobre pressupostos naturalistas a ideia de que os sujeitos humanos devem sua identidade à experiência de um reconhecimento intersubjetivo; por isso, os escritos de Mead seriam os meios mais apropriados encontrados até hoje "para reconstruir as intuições da teoria da intersubjetividade do jovem Hegel num quadro teórico pós-metafísico". Com os meios construtivos da psicologia social de Mead teria sido dada uma inflexão materialista à teoria hegeliana da luta por reconhecimento. Enquanto Hegel desenvolveu a teoria do reconhecimento até chegar a um modelo de conflito de maneira idealista, Mead continuou aquele trabalho, de uma forma que se pode chamar de materialista. E assim, ambos os pensadores referidos, em contraposição à tradição teórica da filosofia política, de Maquiavel e Hobbes até Nietzsche, deram à luta social uma interpretação, digamos, positiva, como força que estrutura a evolução moral da sociedade. A teoria de Mead, como a de Hegel, desembocaria na distinção de três formas de reconhecimento recíproco: primeiro, a esfera da dedicação emotiva; segundo, a das relações amorosas e das amizades; da qual, em terceiro, se distinguem a esfera do reconhecimento jurídico e a do "assentimento solidário".

Honneth registra que essa tripartição da esfera das relações sociais aparece também em outros autores, na sociologia como na filosofia social, tal como nos escritos de Max Scheler (1874-1928), que distinguia entre "comunidade de vida", "sociedade" e a "comunidade de pessoas" fundada na solidariedade, como sendo as três formas essenciais da unidade social. $\mathrm{Na}$ descendência de Scheler, essa compreensão tripartida da integração social aparece também em outros autores da antropologia filosófica alemã do início do século XX - como, por exemplo, em Helmuth Plessner (1892-1985), que, ao pensar os diversos graus de confiança intersubjetiva, distingue três ligações primárias de relacionamento social e de comunidade objetiva. A bastante numerosa lista de interconexões no plano da história teórica parece provar ser plausível subdividir a vida social em três esferas de interação, distinguindo-se as formas de integração social conforme essa se realize "pela via das ligações emotivas, da adjudicação de direitos ou da orientação comum por valores".

Mas, ao reconhecer essa tripartição na realidade, ainda não se pensa o assunto de modo completo. O que haveria a mais, na teoria de Hegel como na de Mead, é que ambos atribuíram às três esferas de interação social padrões distintos de reconhecimento recíproco, aos quais correspondem diferentes potenciais de desenvolvimento moral e de autorrelação individual. A partir das teorias do reconhecimento nas três dimensões da interação social, contidas na filosofia dialética idealista de Hegel e na psicologia social materialista de Mead, Honneth busca uma formulação complementar da intuição desses autores; para tanto, volta a pensar as três

16 Como fonte do nosso resumo neste item, ver Honneth (1992), pp. 121-125 e também pp. 155-159. 
dimensões do reconhecimento como algo que se diferencia conforme se realize na rede dos afetos, na dos direitos ou na da solidariedade.

\section{O reconhecimento na esfera dos afetos: a experiência do amor, o amor de si mesmo e a autoconfiança}

A primeira esfera de reconhecimento se tece no plano dos afetos, entre as pessoas próximas, nas relações primárias. O que acontece primeiro na forma do amor entre mãe e filho, na primeira infância, desenvolve-se ao longo do que se pode chamar de aventura infantil do pré-reconhecimento, e é nesse movimento intersubjetivo em que se constrói, ao mesmo tempo, o amor de si mesmo e a autoconfiança, possibilitados pela experiência do amor do outro e da confiança no amor do outro, formando-se assim a base concreta emotiva para a defesa e reivindicação de direitos, na rede do reconhecimento jurídico, bem como as condições pessoais para a participação no plano da rede de solidariedade e da estima social.

Para falar do "amor", não apenas no sentido restrito que o conceito recebeu desde a valorização romântica da relação íntima sexual, Axel Honneth recomenda um modo e emprego neutro: por relações amorosas devem ser entendidas todas as relações primárias, na medida em que consistam em ligações emotivas fortes entre poucas pessoas, segundo o padrão de relações eróticas entre dois parceiros, de amizades e de relações pais e filho ${ }^{17}$.

A fim de desenvolver uma compreensão mais segura da dinâmica do reconhecimento intersubjetivo na rede afetiva, a análise de Honneth vai remeter à experiência do amor vivenciada na primeira infância, raiz da possibilidade do amor de si mesmo e da autoconfiança. Nessa empreitada, a descrição da "aventura infantil do pré-reconhecimento" toma como referência principal as ideias do psicanalista inglês Donald W. Winnicott $(1896-1971)^{18}$, que desenvolveu seus estudos na perspectiva de um pediatra com formação psicanalítica, no âmbito do tratamento de distúrbios psíquicos e de comportamento, buscando estabelecer conhecimentos sobre as boas condições de socialização das crianças pequenas.

Winnicott concebeu o processo de amadurecimento infantil como uma tarefa que só pode ser solucionada em comum, através da cooperação intersubjetiva de mãe e filho, pois ambos os sujeitos dessa díade estão incluídos no início da vida da criança, no estado de "ser-um simbiótico", e por isso não só a criança, mas também a mãe, mãe e filho "precisam aprender do respectivo outro como têm de diferenciar-se em seres autônomos". Para caracterizar essa primeira fase da relação de comunidade simbiótica, que principia logo depois do nascimento, Winnicott emprega a categoria de "dependência absoluta". Como a mãe e a criança dependem uma da outra nessa fase de unidade simbiótica, esta só pode chegar a um termo quando ambos obtêm para si um pouco de independência. À "des-adaptação gradativa" da mãe corresponde, de parte do bebê, um desenvolvimento intelectual que, junto com a ampliação dos reflexos condicionados, provoca a capacidade de diferenciar cognitivamente o próprio ego e o ambiente.

Para analisar esse segundo estágio da interação, Winnicott adota o conceito "dependência relativa". O autor dedicaria grande parte de sua obra à compreensão dessa fase do desenvolvimento psicológico da criança, pois durante essa fase evolutiva ocorrem muitos dos passos decisivos no desenvolvimento da capacidade infantil para a relação intersubjetiva. Nessa fase se constitui, na relação entre mãe e filho, aquele "ser-em-si-mesmo em um outro", o

17 Ver Honneth (1992), pp. 159-174.

18 Winnicott, membro da corrente mais conciliadora da psicanálise, tem no Brasil o seu nome identificado a estudiosos e institutos reconhecidos, parecendo-me dispensar apresentação. 
qual pode ser concebido como padrão elementar de todas as formas maduras de amor. Se o amor da mãe é duradouro e confiável, a criança é capaz de desenvolver, à sombra de sua confiabilidade intersubjetiva, uma confiança na satisfação social de suas próprias demandas ditadas pela carência; pelas vias psíquicas abertas dessa forma, vai desdobrando, de maneira gradual, uma "capacidade elementar de estar só". A capacidade de estar só é a expressão prática de uma forma de autorrelação individual que outros podem chamar de "autoconfiança": a criança, por se tornar segura do amor materno, alcança uma confiança em si mesma que lhe possibilita estar a sós despreocupadamente. Winnicott atribui a capacidade da criança pequena de estar a sós, no sentido de que ela começa a descobrir de maneira descontraída sua própria vida pessoal, à experiência da existência contínua de uma mãe confiável.

Se o amor representa uma "simbiose quebrada", pela individuação recíproca, o que nele encontra reconhecimento junto ao respectivo outro é apenas sua independência individual. Por causa disso, poder-se-ia criar a ilusão de que a relação amorosa seria caracterizada apenas por uma espécie de reconhecimento com caráter de aceitação cognitiva da autonomia do outro, mas supor isso é errôneo e simplificador. Pois a própria liberação para a independência precisa ser sustentada por uma confiança afetiva na continuidade da dedicação partilhada; sem a segurança emotiva de que a pessoa amada preserva sua afeição, mesmo depois da autonomia renovada, para o sujeito que ama não seria possível o reconhecimento de sua independência.

É a psicologia que mostra, pois, que toda relação amorosa, seja entre pais e filho, seja aquela relação contida na experiência da amizade, seja, finalmente, também, a que acompanha o contato íntimo, está ligada à condição de simpatia e atração, que não se submete inteiramente ao domínio do indivíduo. Os sentimentos positivos para com outros seres humanos são sensações involuntárias, e a relação amorosa não se aplica indiferentemente a um maior número de parceiros. Mas embora seja inerente ao amor um elemento necessário de "particularismo moral", Honneth concorda com Hegel ao considerar o amor como sendo o cerne estrutural de toda eticidade: só aquela ligação simbioticamente alimentada, que surge da delimitação desejada reciprocamente, cria a medida da autoconfiança individual, que pode tornar-se base indispensável para a participação autônoma na vida pública.

\section{O reconhecimento na esfera dos direitos: a justiça e o respeito universal}

Da forma de reconhecimento do amor tal como apresenta Honneth, com auxílio da teoria psicológica na visão psicanalítica de Winnicott, distingue-se a relação jurídica. O desenvolvimento das leis acompanha a evolução da consciência dos direitos, e esse é o plano do reconhecimento jurídico, que se dá de modo diferente da forma de reconhecimento afetivo a que nos referimos. A distinção entre reconhecimento afetivo e reconhecimento jurídico atravessa muitos aspectos. Nesse ponto da análise do plano das relações jurídicas, Honneth continua mantendo suas referências principais - Hegel e Mead. No que concerne ao direito, ambos perceberam que só podemos chegar a uma compreensão de nós mesmos como portadores de direitos quando sabemos quais obrigações temos de observar em face do outro. Da perspectiva normativa de um "outro generalizado", que nos ensina a reconhecer os outros membros da coletividade como portadores de direitos, passamos a nos entender também como pessoas de direito, e é assim que nos tornamos seguros do cumprimento social de algumas de nossas pretensões.

Embora saliente o que têm em comum, Honneth faz distinções entre as teses de Hegel e de Mead quanto à rede jurídica de reconhecimento. Mead, com seu conceito de "outro generalizado", pareceria estar interessado na lógica do reconhecimento jurídico como tal. A 
psicologia social de Mead apresentava o conceito de "reconhecimento jurídico" como a relação em que "o Alter e o Ego se respeitam mutuamente como sujeitos de direito", pois conhecem e partilham normas sociais por meio das quais os direitos e os deveres se distribuem de modo legítimo na comunidade ${ }^{19}$.

De sua parte, com a forma de reconhecimento do direito, Hegel visava à constituição específica das relações jurídicas modernas, visto que só a sua pretensão se estende, por princípio, a todos os homens na qualidade de seres iguais e livres. Um respeito universalista não deve ser concebido como uma atitude ligada às emoções; é operação do entendimento, cognitiva, que põe limites às sensações afetivas, assim constituindo um tipo de respeito que, embora desligado dos sentimentos de simpatia e afeição, deve poder dirigir o comportamento individual. Não é óbvio interpretar como os sujeitos chegam a reconhecer-se de modo recíproco em sua imputabilidade moral, sob as condições jurídicas modernas. Tal propriedade, que todos devem partilhar, resulta do "status de uma pessoa imputável", independente de suas capacidades humanas mais definidas.

$\mathrm{Na}$ época moderna, o reconhecimento como pessoa de direito tende a aplicar-se a todo sujeito na mesma medida; os direitos individuais se desligam das expectativas concretas específicas dos papéis sociais, uma vez que agora competem, em igual medida, a todo homem na qualidade de ser livre, de modo independente do grau da estima social. Afirma-se, assim, um novo caráter do reconhecimento jurídico e originam-se duas formas distintas de respeito: o reconhecimento jurídico aparece como a expressão de que todo ser humano, sem distinção, deve ser considerado um "fim em si"; por outro lado, o "respeito social" salienta o "valor" do indivíduo singular medido pelos critérios de relevância social. No primeiro caso, trata-se de um respeito universal, em vista da liberdade de vontade da pessoa; no segundo, levam-se em conta qualidades e realizações individuais, na medida em que são consideradas socialmente relevantes.

O fato de podermos reconhecer a um ser humano como pessoa, sem ter de estimá-lo por suas realizações ou por seu caráter, indica, pois, a distinção entre duas formas de respeito: o respeito de um ser humano como pessoa é uma espécie de reconhecimento cognitivo; desse reconhecimento da pessoa como tal distingue-se a estima por um determinado ser humano; no caso do respeito a um ser humano particular, já não estão em jogo apenas normas gerais, sabidas por intuição; trata-se agora da avaliação de um ser humano com propriedades pessoais e capacidades concretas, o que supõe dispormos do apoio de um sistema referencial valorativo, que informa sobre o valor de traços da personalidade, numa escala de graduação, de melhor ou pior. Para o reconhecimento jurídico, o problema é determinar aquela propriedade geral das pessoas como tais; para a estima social, o que está em questão é o sistema referencial valorativo, no interior do qual se mede o "valor" das virtudes dos indivíduos.

Toda comunidade jurídica moderna está fundada na presunção da imputabilidade moral de todos os seus membros. A ampliação cumulativa de pretensões jurídicas individuais, com a qual vêm tendo de lidar as sociedades modernas, pode ser entendida como um processo no qual a extensão das propriedades universais de uma pessoa moralmente imputável foi aumentando, passo a passo, sob a pressão de uma luta por reconhecimento. Nas ciências do direito, aos poucos, foi-se afirmando a distinção dos direitos subjetivos em direitos liberais, de liberdade, direitos políticos, de participação, e direitos sociais, de bem-estar. A primeira categoria de direitos se refere aos direitos negativos que protegem a pessoa de intervenções desautorizadas do Estado, com vistas à salvaguarda de sua liberdade, sua vida e sua propriedade. A segunda categoria de direitos se refere aos direitos positivos, que cabem à pessoa com vistas à participação em processos políticos. A terceira categoria abrange aqueles direitos, igualmente positivos, que permitem à pessoa ter parte, de modo equitativo, na distribuição de bens básicos. Essa tripartição dos direitos ainda se encontra presente nas discussões atuais. Os 
direitos políticos de participação surgiram, talvez, como produto secundário dos direitos de liberdades, que já haviam sido em geral "atribuídos à parte masculina da população adulta" no século XVIII; e com os direitos políticos de participação surgiram também os direitos de bemestar, na sequência de uma ampliação forçada "a partir de baixo".

A apresentação de Honneth evoca, nesse ponto, como ao mesmo tempo próxima e complementar, a que é realizada por Norberto Bobbio, ao analisar a evolução dos direitos modernos. Bobbio também deu à compreensão desse processo uma inflexão histórica, considerando mesmo que os direitos podem ser vistos como a característica definidora desse tempo que veio a chamar de "era dos direitos" 20 . O conhecido filósofo político e jurista italiano deixou bem explícita sua compreensão de que os direitos do homem, por mais fundamentais que sejam, são direitos históricos, ou seja, "nascidos em certas circunstâncias, caracterizadas por lutas em defesa de novas liberdades contra velhos poderes, e nascidos de modo gradual, não todos de uma vez e nem de uma vez por todas" (Bobbio, 1992, p. 5).

Olhando os direitos modernos como conquistas históricas que se desejam impor como "direitos do homem" - a serem, portanto, respeitados acima de tempo e lugar, Bobbio identificou as diversas gerações de direitos conquistados pelos homens modernos: na "primeira geração" de direitos encontram-se as liberdades, das quais a primeira afirmada, na origem de todo o processo de afirmação de direitos humanos, foi a liberdade religiosa, conquistada como um efeito das guerras de religião. À liberdade religiosa seguiram-se as liberdades civis, da luta dos parlamentos contra os soberanos absolutos; depois, a liberdade política e as liberdades sociais, oriundas do nascimento, crescimento e amadurecimento do movimento dos trabalhadores assalariados, dos camponeses com pouca ou nenhuma terra, dos pobres que exigem dos poderes públicos não só o reconhecimento da liberdade pessoal e das liberdades negativas, mas também a proteção do trabalho contra o desemprego, os primeiros rudimentos de instrução contra o analfabetismo, depois, a assistência para a invalidez e a velhice. Ao lado dos direitos sociais, chamados de "direitos de segunda geração", Bobbio observou a emergência, em período recente, de "direitos de terceira geração", que julgava constituírem uma categoria ainda heterogênea e vaga, o que impedia compreender sua verdadeira significação. Entre esses direitos novos de terceira geração, julgava ser o mais importante "o reivindicado pelos movimentos ecológicos: o direito de viver num ambiente não poluído". O pensador italiano ainda conseguiu vislumbrar emergências que julgou poderem ser chamadas de "direitos de quarta geração", referentes, por exemplo, aos efeitos da pesquisa biológica, que permite e permitirá, cada vez mais, manipulações do patrimônio genético de cada indivíduo. Os avanços da pesquisa científica e da capacidade tecnológica da medicina, por exemplo, questões que se têm afirmado como de "bioética", configurariam um âmbito novo de direitos que, se postos nessa sequência ligada à história moderna da afirmação de direitos, seriam os de "quarta geração".

\section{O reconhecimento na esfera da estima social: características, realizações e solidariedade}

Tanto Hegel como Mead, na visão de Honneth, distinguiram do amor e da relação jurídica uma terceira forma de reconhecimento recíproco, que descreveram de maneira diversa, mas com algumas concordâncias, sobretudo no que se refere à definição de sua função, pois os sujeitos humanos precisam, além da experiência da dedicação afetiva e do reconhecimento

20 No livro, justamente, assim intitulado, conforme Bibliografia. 
jurídico, de uma estima social que lhes permita referir-se positivamente a suas propriedades e capacidades concretas ${ }^{21}$.

Ainda a partir das contribuições de Hegel e de Mead, Honneth conclui que um padrão de reconhecimento dessa espécie, cuja substância seja a estima mútua, logo, que vá além dos afetos e também da rede jurídica dos direitos, só se torna compreensível quando houver, por trás dele, um horizonte de valores partilhado entre si pelos sujeitos envolvidos. Já na apresentação do reconhecimento jurídico o autor indicava a distinção entre o reconhecimento com base em leis e direitos e a rede da estima social, baseada em qualidades e realizações individuais, que vão ser expostas e reconhecidas no plano das relações intersubjetivas ou sociais.

Por mais diferentes que fossem os modos de abordagem da realidade empírica e de trabalho conceitual, Honneth afirma que tanto Hegel quanto Mead trabalharam com essa distinção: Hegel, com seu conceito de "eticidade", e Mead, com sua ideia de uma divisão democrática do trabalho, ambos tentaram caracterizar um tipo particularmente exigente de comunidade de valores, em cujo quadro situa-se a forma de reconhecimento por estima. De modo diferente do reconhecimento jurídico em sua forma moderna, a estima social se aplica às qualidades particulares que caracterizam os seres humanos em suas diferenças pessoais. Enquanto o direito moderno representa um meio de reconhecimento que expressa propriedades universais de sujeitos humanos, a forma de reconhecimento por estima requer um meio social que avalie as diferenças de capacidades e qualidades entre sujeitos humanos, fundamentando os vínculos intersubjetivos. Essa tarefa de mediação é operada, no nível social, por um quadro de orientações simbolicamente articulado, embora sempre aberto, poroso, no qual se formulam valores e objetivos éticos, cujo todo constitui a autocompreensão cultural de uma sociedade. Tal quadro de orientações serve de sistema referencial para a avaliação de propriedades da personalidade, cujo "valor" social se mede pelo grau em que parecem estar em condições de contribuir à realização dos objetivos sociais.

A autocompreensão cultural de uma sociedade predetermina os critérios pelos quais se orienta a estima social das pessoas, já que suas capacidades e realizações são julgadas intersubjetivamente, conforme a medida em que cooperaram na implementação de valores culturalmente definidos. Nesse sentido, essa forma de reconhecimento recíproco está ligada à pressuposição de um contexto de vida social, cujos membros constituem uma comunidade de valores, mediante a orientação por "concepções de objetivos comuns", e as formas que essa comunidade pode assumir são tão variáveis historicamente quanto as do reconhecimento jurídico. Quanto mais as concepções dos objetivos éticos se abrem a diversos valores, e quanto mais a ordenação hierárquica cede a uma concorrência horizontal, tanto mais a estima social assumirá um traço individualizante e criará relações simétricas.

Assim como a relação jurídica, a estima social só pôde assumir a forma que hoje nos é familiar depois que se desenvolveu a ponto de não caber mais nas condições-limite das sociedades articuladas em estamentos, tais como eram as sociedades pré-modernas. A mudança estrutural em marcha foi marcada, no plano da história conceitual, pela transição dos conceitos de "honra", ou de "origem", que se relacionam ao lugar social obtido por nascimento, às categorias da "reputação" ou do "prestígio" social, que se referem ao resultado da participação individual. Através das análises da sociologia no século XX, foi-se registrando a transformação da dinâmica da estima social que paulatinamente se distancia do critério da honra e da hierarquia. Com a modificação operada na modernidade, com a afirmação da autonomia dos indivíduos, foi-se passando do critério da honra ao da reputação e ao do prestígio, e, finalmente, tomar forma no conceito-síntese de status social. Nessa esfera da estima social, que, em outro tempo, pôde chamar-se de honra e ser ligada ao estamento, e hoje é do status social, ligada às características da atividade e à dinâmica do reconhecimento intersubjetivo, os

21 Aqui nosso resumo tem por base Honneth (1992), pp. 198-211. 
indivíduos, hoje como ontem, embora de modo diferente, vão tentar conquistar e medir o seu valor social.

Segundo Honneth, uma tensão especial dessa sociedade e desse tempo impregna a forma moderna de organização da estima social, submetendo-a de modo duradouro a um conflito cultural. Trata-se de um conflito cultural de longa duração, pois

nas sociedades modernas, as relações de estima social estão sujeitas a uma luta permanente na qual os diversos grupos procuram elevar, com os meios da força simbólica e em referência às finalidades gerais, o valor das capacidades associadas à sua forma de vida (Honneth, 2003, p. 207).

Assim, tem-se hoje que a afirmação na rede dinâmica da estima social não se faz apenas no registro da dinâmica intersubjetiva e do reconhecimento das capacidades e realizações individuais, mas na dinâmica dos grupos que representam formas de vida, como afirmação e conquista de estima social de grupos ou "movimentos sociais". Quanto mais os movimentos sociais conseguem chamar a atenção da esfera pública para a importância das capacidades por eles representadas, de modo coletivo, tanto mais existe a possibilidade de elevar na sociedade o valor social do grupo que representam - dito de outro modo, elevar a reputação de seus membros. $\mathrm{O}$ autor não deixa de registrar que as relações de estima social estão associadas, embora de forma indireta, aos padrões de distribuição de renda, o que parece bem evidente; em consequência, os confrontos econômicos pertencem de modo constitutivo a essa forma de luta por reconhecimento. A esse respeito, sobre o elo entre as redes da situação econômica e da estima social, Honneth refere especialmente as contribuições de Georg Simmel ${ }^{22}$.

Partindo das ideias de Hegel e de Mead sobre as três redes de reconhecimento afetiva, jurídica e social -, com a sociologia do reconhecimento, Honneth tem em mente esclarecer sobre a "solidariedade", porque se recomenda a "solidariedade" como um conceito genérico para a questão; para tanto, julga necessário antecedê-la pela consideração do tipo de autorrelação individual concomitante com a experiência da estima social. Enquanto a forma de reconhecimento de estima social é organizada por estamentos, a experiência da distinção social correspondente, em grande medida, tem a ver com a identidade coletiva do grupo a que pertence o indivíduo. As realizações, por cujo valor social o indivíduo pode ver-se reconhecido, ainda não se distinguem das propriedades coletivas típicas do seu estamento; por isso, não pode sentir-se destinatário da estima como sujeito individual, mas o depositário da estima social é o grupo em sua totalidade. A autorrelação prática a que essa experiência de reconhecimento leva os indivíduos é um sentimento de orgulho de grupo, de honra coletiva. Na relação interna de tais grupos, as formas de interação assumem o caráter de relações solidárias, e por solidariedade se compreende uma relação interativa em que os sujeitos tomam interesse, de modo recíproco, por seus modos distintos de vida, já que se estimam de maneira simétrica.

O conceito de "solidariedade" se aplica especialmente às relações de grupo que se originam na experiência de circunstâncias difíceis, negativas. É o que se dá, por exemplo, em situações de resistência comum contra a repressão política, quando a concordância no objetivo prático, predominando sobre tudo, gera um horizonte intersubjetivo de valores, no qual cada um aprende a reconhecer, na mesma medida, o significado das capacidades e propriedades do outro. Esse mecanismo da estima simétrica pode explicar também o fato de a guerra às vezes representar

um acontecimento coletivo capaz de fundar relações espontâneas de interesse solidário para além dos limites sociais (...) Na experiência partilhada de grandes fardos e privações, origina-se uma nova estrutura de valores que permite aos sujeitos estimarem-se

22 Pode-se supor que o autor esteja se referindo a Soziologie. Untersuchungen über die Formen der Vergesellschaftung, obra incluída na lista bibliográfica do seu livro em estudo. Cabe lembrar também o famoso trabalho Philosophie des Geldes (Filosofia do dinheiro), de 1900 . 
mutuamente por realizações e capacidades que antes não tinham importância social (Honneth, 2003, pp. 209-210).

Para além dessa espécie de autorrelação prática, em que a estima social é vivenciada segundo o modelo estamental, com o desenvolvimento moderno da individuação, modifica-se a relação prática consigo próprio, em que a estima social encaminha os sujeitos. O indivíduo passa a referir a si próprio o respeito social que goza por suas realizações, aos olhos dos demais membros da sociedade; não se confunde mais com seu grupo, ou seja, não mais se identifica inteiramente com a estima social do grupo. Desse dinamismo decorrem expressões da autorrealização prática que na linguagem comum passam como "sentimento do próprio valor", de "autoestima", expressões paralelas com os conceitos antes atribuídos à rede afetiva e à rede jurídica de reconhecimento, respectivamente, de "autoconfiança" e de "autorrespeito".

Sob as condições das sociedades modernas, a solidariedade se liga ao pressuposto de relações sociais de estima simétrica entre sujeitos individualizados (e autônomos). Estimar-se simetricamente, nesse sentido, significa considerar-se reciprocamente à luz de valores que fazem as capacidades do outro parecer significativas para a ação comum. Relações dessa espécie podem chamar-se solidárias porque despertam a tolerância ante a particularidade individual de outra pessoa, mas também pelo interesse por essa particularidade: na medida em que cuido ativamente das capacidades do outro, cuido que aquelas suas propriedades possam desenvolverse; logo, nossos objetivos comuns passam a ser realizáveis.

Ao concluir seu esquema das três esferas distintas na estrutura das relações sociais de reconhecimento, Honneth explica a expressão que usa - "simétrico", como devendo-se entender no sentido de que, nesses nossos tempos modernos, todo sujeito recebe a chance de fazer a experiência de si mesmo, em suas próprias realizações e capacidades, como valioso para a sociedade; por isso, só as relações sociais que se podem traduzir pelo conceito de solidariedade "podem abrir o horizonte em que a concorrência individual por estima social assume uma forma isenta de dor, isto é, não turvada por experiências de desrespeito" (Honneth, 2003, p. 211).

\section{Algumas considerações finais}

Tal reflexão sobre as dinâmicas do reconhecimento, que faz um uso peculiar e associa as clássicas versões de teoria de reconhecimento dos séculos XIX e XX, dá-nos a esperança de compreender melhor, de um modo novo e criativo, a realidade social atual que aguarda e, às vezes, assusta as novas gerações oriundas da escola e em busca de inserção econômica e social. Parece evidente, já a partir da experiência do cidadão comum, e, é de se esperar, ainda mais na condição do observador interessado no conhecimento e na reflexão sobre as tramas da vida social, que a inserção no mundo do trabalho, sobretudo, no mutante mercado do emprego, com suas dimensões afetivas, jurídicas e sociais, exerce influência na formação das condições de sobrevivência. Portanto, parece correto supor que serão determinantes na manutenção das condições de reconhecimento e na dinâmica da solidariedade, influenciando a conformação das condições de vivência da estima social, logo, da autoestima dos sujeitos envolvidos. Trabalho, desemprego e autoestima parecem apresentar ligações evidentes, fortes e múltiplas, e suas interconexões parece fácil supor. O problema é: qual seria exatamente essa interconexão?

Por mais que as duas primeiras esferas de reconhecimento estejam alimentadas por boas condições na experiência infantil, e pelas modernas leis igualitárias, ante as mudanças no mundo do trabalho com novas formas de organização da atividade e novas dependências econômicas, a forma da convivência em grupo pode vir a ser tão atingida que não seja óbvio construir um lugar digno na esfera da estima social requerida para o reconhecimento 
intersubjetivo. Para corrigir as possíveis distorções provocadas nas novas estruturas de reconhecimento, em tempos de tempestade nas estruturas sociais, exige-se muita lucidez e um grande esforço de adaptação, como tarefa coletiva, o que concerne sobremaneira aos estudiosos da psicologia social e aos profissionais da educação. A consciência das três dimensões da dinâmica social do reconhecimento, a meu ver, pode inspirar novas direções de pesquisa e contribuir para o encontro de soluções práticas ante os desafios do presente.

\section{Referências}

Albornoz, S. G. (2008). Sobre O direito à preguiça de Paul Lafargue. Cadernos de Psicologia Social do Trabalho, 11 (1), $1-17$.

Albornoz, S. G (2009). Jogo e trabalho: do homo ludens de Johann Huizinga ao ócio criativo de Domenico De Masi. Cadernos de Psicologia Social do Trabalho, 12 (1), 75-92.

Albornoz, S. G. (2010). Tempo livre e humanização: dúvidas e esperanças ante as novas possibilidades de lazer. Cadernos de Psicologia Social do Trabalho, 13 (1), 89-101.

Arendt, H. (1981). A condição humana. Rio de Janeiro: Forense.

Arendt, H. (1983). A dignidade da política. Rio de Janeiro: Relume-Dumará.

Bloch, E. (2006). O princípio esperança (vol. 2). Rio de Janeiro: Contraponto.

Bobbio, N. (1992). A era dos direitos. Rio de Janeiro: Campus.

Hegel, G. W. F. (1970). Jenaer Schriften, 1801-07. Werke in 20 Bänden (vol. 2). Frankfurt: Suhrkamp.

Honneth, A. (2003). Luta pelo reconhecimento: a gramática moral dos conflitos sociais. Rio de Janeiro: Editora 34.

\section{Endereço para correspondência}

albornoz.suzanaguerra@gmail.com 